\title{
Signo del engrosamiento septal arrosariado
}

\section{Beaded septum sign}

\author{
Ana Cristina Manzano, MD. (1), Carlos Andrés Celis Preciado, MD. ${ }^{(2)}$
}

(1)Radióloga, Departamento de Radiología, Hospital Universitario San Ignacio. Bogotá, Colombia.

${ }^{(2)}$ Internista, Neumólogo, Unidad de Neumología, Hospital Universitario San Ignacio. Pontificia Universidad Javeriana. Bogotá, Colombia

Correspondencia: Ana Cristina Manzano, correo electrónico: crispetamanzano@ gmail.com

Recibido:16/04/14. Aceptado: 10/06/14.
En su Glosario de Términos de Radiología Torácica, la Sociedad Fleischner lo define como el engrosamiento nodular e irregular de los septos interlobulillares, que recuerda un collar de cuentas (1).

El signo escanográfico fue descrito en 1989 por Ren et al., quienes realizaron tomografía computadorizada de alta resolución a 180 especímenes pulmonares preparados mediante un método que permitía correlación radiológico-patológica
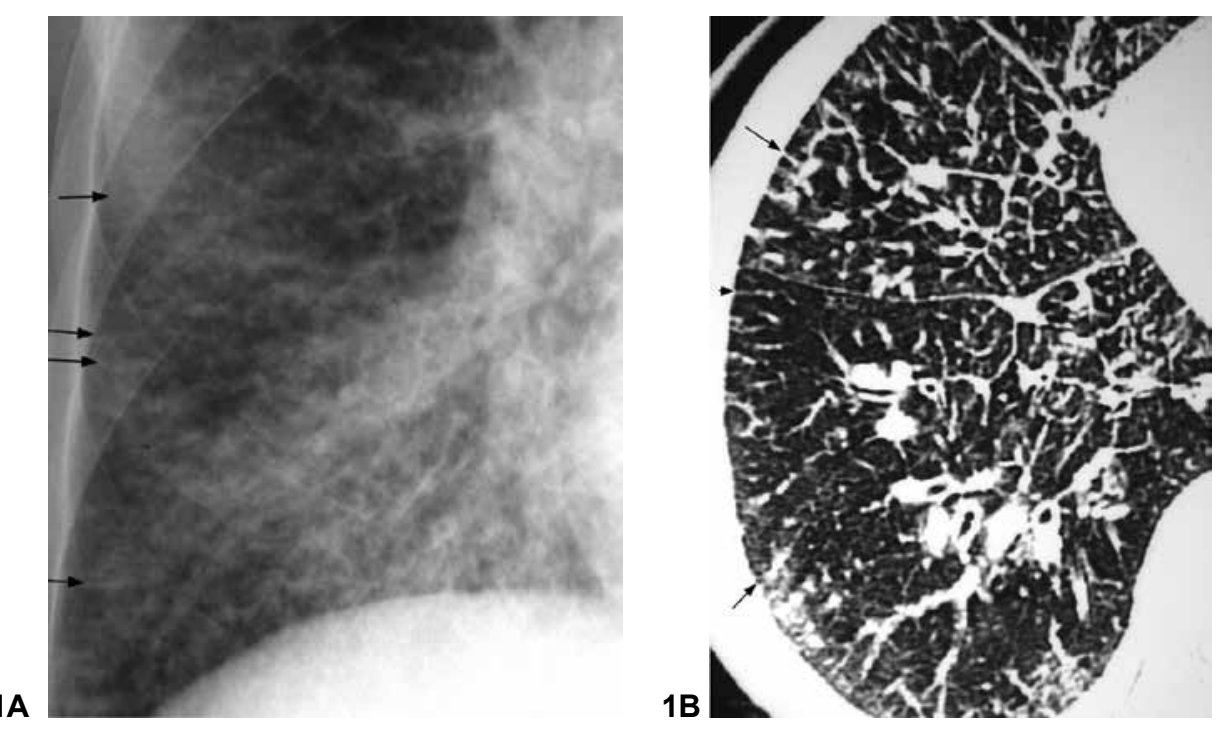

Figura 1A y 1B. Signo del engrosamiento arrosariado. Las flechas señalan el engrosamiento nodular de múltiples septos interlobulillares en la periferia del pulmón derecho, en un paciente con carcinomatosis linfangítica por carcinoma gástrico. uno a uno. De aquellos pulmones, 32 presentaban metástasis y en 19 de ellos se observó el signo, que correspondía a crecimiento directo del tumor en los capilares y linfáticos y en el intersticio septal. No se encontró en ningún caso de edema pulmonar o fibrosis o en pulmón sano (2). Dicho hallazgo, fue confirmado posteriormente (3-4).

El signo también se ha descrito en sarcoidosis (5). 


\section{Bibliografía}

1. Hansell DM, Bankier AA, MacMahon H, McLoud TC, Muller NL, Remy J. Fleischner Society: glossary of terms for thoracic imaging. Radiology. 2008;246:697-722.

2. Ren H, Hruban RH, Kuhlman JE, et al. Computed tomography of inflation-fixed lungs: the beaded septum sign of pulmonary metastases. J Comput Assist Tomogr. 1989;13:411-6.
3. Paslawski M, Krzyzanowski K, Zlomaniec J. Lymphangitis carcinomatosa in thin section computed tomography. Ann Univ Mariae Curie Sklodowska Med. 2004;59:1-5.

4. Stein MG, Mayo J, Muller N, Aberle DR, Webb WR, Gamsu G. Pulmonary lymphangitic spread of carcinoma: appearance on CT scans. Radiology. 1987;162:371-5.

5. Murdoch J, Muller NL. Pulmonary sarcoidosis: changes on follow-up CT examination. AJR Am J Roentgenol. 1992;159:473-7. 